\title{
Membrane Fouling Potential of Secondary Effluent Organic Matter (EfOM) from Conventional Activated Sludge Process
}

\author{
Chun-Hai Wei* and Gary Amy
}

Water Desalination and Reuse Center, 4700 King Abdullah University of Science and Technology (KAUST), Thuwal 23955-6900, Saudi Arabia

\begin{abstract}
Secondary effluent organic matter (EfOM) from a conventional activated sludge process was filtered through constant-pressure dead-end filtration tests with a sequential ultrafiltration (UF, molecular weight cut-off (MWCO) of 10k Dalton) and nanofiltration (NF, MWCO of 200 Dalton) array to investigate its membrane fouling potential. Advanced analytical methods including liquid chromatography with online carbon detection (LC-OCD) and fluorescent excitationemission matrix (F-EEM) were employed for EfOM characterization. EfOM consisted of humic substances and building blocks, low molecular weight (LMW) neutrals, biopolymers (mainly proteins) and hydrophobic organics according to the sequence of their organic carbon fractions. The UF rejected only biopolymers and the NF rejected most humics and building blocks and a significant part of LMW neutrals. Simultaneous occurrence of cake layer and standard blocking during the filtration process of both UF and NF was identified according to constant-pressure filtration equations, which was possibly caused by the heterogeneous nature of EfOM with a wide MW distribution (several ten to several million Dalton). Thus the corresponding two fouling indices ( $k_{c}$ for cake layer and $k_{s}$ for standard blocking) from UF and NF could characterize the fouling potential of macromolecular biopolymers and low to intermediate MW organics (including humics, building blocks, LMW neutrals), respectively. Compared with macromolecular biopolymers, low to intermediate MW organics exhibited a much higher fouling potential due to their lower molecular weight and higher concentration.
\end{abstract}

Keywords: Biopolymers, cake layer, F-EEM, LC-OCD, standard blocking.

\section{INTRODUCTION}

Membrane technologies in terms of microfiltration (MF), ultrafiltration (UF), nanofiltration (NF) and reverse osmosis (RO) have been receiving increasing attention in the application to tertiary treatment and reuse of biologically treated secondary effluent from a wastewater treatment plant (WWTP). Generally, biologically treated secondary effluent consists of fine particulate suspended solids, organic/inorganic colloids and solutes [1]. Among them, the organic colloids and solutes, defined as effluent organic matter (EfOM), can be considered as the main foulants especially for UF, $\mathrm{NF}$ and RO [2]. Therefore, an investigation on the fouling potential of EfOM is necessary to develop effective solutions to control membrane fouling.

As a complex matrix, EfOM usually consists of microbial products, refractory compounds, residual substrate, intermediates and end products [1]. These components play different roles in membrane fouling due to their individual characteristics such as size, charge, hydrophobicity, etc. Thus, conventional aggregate parameters such as total organic carbon (TOC) and chemical oxygen demand (COD) are inadequate in providing detailed information on EfOM. As a recent development, liquid chromatography with

\footnotetext{
*Address corresponding to this author at the Water Desalination and Reuse Center, 4700 King Abdullah University of Science and Technology (KAUST), Thuwal 23955-6900, Saudi Arabia; Tel: +966-2-808-2167;

E-mail: chunhai.wei@kaust.edu.sa
}

on-line organic carbon detection (OCD), on-line organic nitrogen detection (OND), and on-line ultraviolet detection (UVD) (still abbreviated as LC-OCD for simplification) has been established to characterize water-soluble organics more deeply [3]. These three synchronous signals can provide more detailed information on all hydrophilic fractions (such as biopolymers, including polysaccharides and proteins, humics, building blocks, and low molecular weight substances) than the previous single signal (OCD) and/or two signals (OCD and UVD) [4]. In addition, three dimensional fluorescence excitation-emission matrix (F-EEM) has also been used in EfOM characterization [5]. F-EEM can monitor the changes of fluorescent substances such as proteins and humics due to its high selectivity and sensitivity. Thus, the analyses of LC-OCD and F-EEM are useful to understand more details on EfOM characteristics.

Several models [6-10] have been developed to describe the membrane fouling during constantpressure filtration process. Among them, three kinds of blocking models (complete blocking, standard blocking and intermediate blocking) and the cake filtration model (illustrated in Figure 1), described by Equation (1)-(4), respectively, have been commonly used to analyze the constant-pressure dead-end membrane filtration process for MF [11], UF [12], and even NF/RO [13].

$$
\frac{d(V / A)}{d t}=J_{0}-k_{b}(V / A)
$$




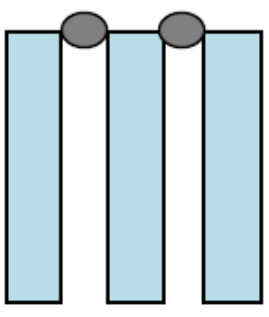

Complete blocking

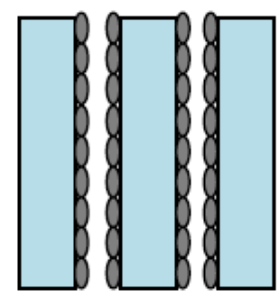

Standard blocking

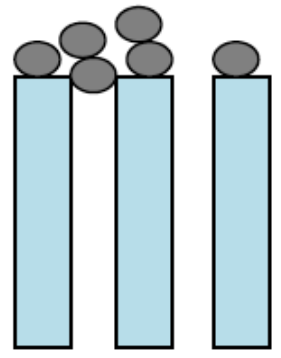

Intermediate blocking

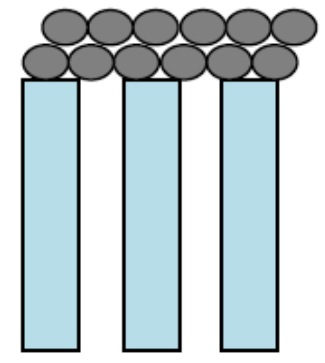

Cake layer

Figure 1: Schematic diagram of fouling models under constant-pressure dead-end filtration.

$\frac{t}{V / A}=\frac{1}{J_{0}}+\frac{k_{s}}{2} t$

$\frac{d t}{d(V / A)}=\frac{1}{J_{0}}+k_{i} t$

$\frac{t}{V / A}=\frac{1}{J_{0}}+\frac{k_{c}}{2}(V / A)$

In these equations, $t$ is the filtration time, $V$ is the cumulative permeate volume, $A$ is the effective filtration area, $\mathrm{J}_{0}$ is the initial flux, $\mathrm{k}_{\mathrm{b}}, \mathrm{k}_{\mathrm{s}}, \mathrm{k}_{\mathrm{i}}, \mathrm{k}_{\mathrm{c}}$ (i.e., the wellknown modified fouling index) are the coefficients of complete blocking, standard blocking, intermediate blocking, and cake filtration models, respectively. From these equations, four data plots have been proposed where the linearity of the filtration data in the plot of $\mathrm{d}(\mathrm{V} / \mathrm{A}) / \mathrm{dt} \sim \mathrm{V} / \mathrm{A}, \mathrm{t} /(\mathrm{V} / \mathrm{A}) \sim \mathrm{t}, \mathrm{dt} / \mathrm{d}(\mathrm{V} / \mathrm{A}) \sim \mathrm{t}$ and $\mathrm{t} /(\mathrm{V} / \mathrm{A}) \sim$ $\mathrm{V} / \mathrm{A}$ offers proof of the complete blocking, standard blocking, intermediate blocking, and cake filtration model, respectively [12]. In these equations, V/A in place of $\mathrm{V}$ is used in order to compensate for the effects of the different membrane areas in this study.

In this study, the fouling potential of EfOM from biologically treated secondary effluent from the Jeddah WWTP was investigated through constant-pressure dead-end filtration tests with a sequential UF and NF array. Advanced analytical methods including LC-OCD and F-EEM were employed to characterize the changes of EfOM before and after filtration for a better understanding of its fouling potential.

\section{MATERIAL AND METHODS}

\subsection{Experimental Set-Up}

Biologically treated secondary effluent from AlRuwais municipal WWTP in Jeddah, which employed anoxic/aerobic activated sludge process with internal sludge recycle for nitrification and denitrification, was sampled and pre-filtered by a Whatman $1.2 \mu \mathrm{m}$ glass fibre syringe filter in order to remove suspended solids and thus obtain an EfOM sample for the following characterization and fouling study.

The lab-scale constant-pressure dead-end filtration system used in this study is illustrated schematically in Figure 2. Using compressed nitrogen, the EfOM sample to be filtered was pressurized in a stainless steel tank (effective volume $3.75 \mathrm{~L}$ ) up to the preset value. The permeate from the filtration cell was collected in a tank on the electronic balance connected to the computer. The permeate weight was recorded at certain intervals and then converted to volume with permeate density correlations. The instantaneous filtration rate was obtained by numerical differentiation of the permeate volume vs. filtration time.

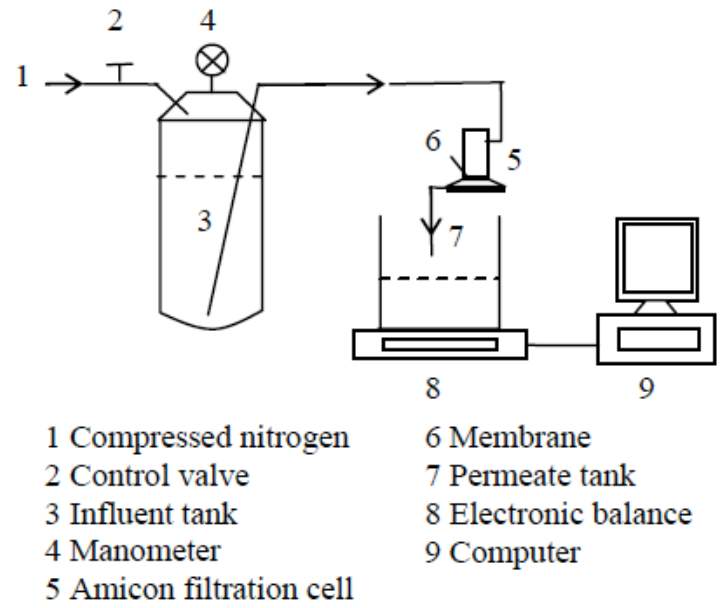

Figure 2: Schematic diagram of constant-pressure dead-end filtration system in this study.

The EfOM sample was first filtered through a Millipore regenerated cellulose UF with a molecular weight cut-off (MWCO) of 10k Dalton (abbreviation $\mathrm{RC10kD)}$ in an Amicon 8010 unstirred cell under 4.7 bar (i.e., the maximum value recommended by membrane manufacturer), and then the permeate of UF was filtered through a Koch acid/base stable NF 
with a MWCO of 200 Dalton (product designation SelRO ${ }^{\circledR}$ MPF-34, abbreviation MPF200D) in an Amicon 8050 unstirred cell under 5 bar. The temperature was kept constant at $20^{\circ} \mathrm{C}$ during filtration. Before filtration, the membrane was soaked in Milli-Q water for rinsing and then conditioned through filtering Milli- $\mathrm{Q}$ water at preset pressure for at least $2 \mathrm{~h}$.

\subsection{Analytical Methods}

A LC-OCD (Model 8, DOC-LABOR, Germany) with a size exclusive chromatography (SEC) column filled with Toyopearl resin (HW-50S) was used to characterize the hydrophilic fractions of EfOM according to the molecular weight (MW) corresponding to the retention time in the SEC column. The chromatographic (i.e., hydrophilic) fractions were commonly detected as follows [3]: biopolymers (including polysaccharides, proteins and aminosugars) with $\mathrm{MW}>20 \mathrm{kD}$ (retention time in 26-38 min), humics (HS) with MW of 500-1 kD (retention time in 40-46 $\mathrm{min}$ ), building blocks (i.e., breakdown products of humics) with MW of 300-500 D (retention time 46-53 min), low molecular weight (LMW) acids and HS with $\mathrm{MW}<350 \mathrm{D}$ (retention time 53-57 min) and LMW neutrals (including mono-oligosaccharides, alcohols, aldehydes, ketones) with $\mathrm{MW}<350 \mathrm{D}$ (retention time > $57 \mathrm{~min}$ ). When one sample was measured, the sample was split into two fractions automatically. One fraction went directly to three detectors - ultraviolet detector (UVD), organic carbon detector (OCD) and organic nitrogen detector (OND) - sequentially, where the UVD measured the spectral adsorption coefficient at 254 $\mathrm{nm}$, the OCD oxidized all organic matter in a thin film UV reactor and measured OC in terms of the produced $\mathrm{CO}_{2}$ by a non-dispersive infrared detector, and the OND oxidized all organic and inorganic nitrogen into nitrate and measured total nitrate using another UVD at $220 \mathrm{~nm}$. Thus the aggregate parameters of the sample $\left(\mathrm{UV}_{254}, \mathrm{TOC}\right.$ and Total Nitrogen) could be measured. The other fraction went first into the SEC column, in which hydrophilic fractions were eluted by the mobile phase (the solution of potassium dihydrogen phosphate and sodium hydrogen phosphate dihydrate) at different times related to their molecular weight while hydrophobic fractions were retained and not eluted, and then the hydrophilic fractions carried with mobile phase flowed into three detectors sequentially to measure the $\mathrm{UV}_{254}, \mathrm{OC}$ and $\mathrm{ON}$ for each fraction. Thus the hydrophobic $O C$ could be quantitatively calculated from the TOC minus the total hydrophilic OC based on the calibration using standard substances (Suwannee River Standard II humic acids and fulvic acids for molecular weight calibration; potassium hydrogen phthalate and potassium nitrate for detector calibration). Further details on how LC-OCD works and the recovery of detectors can be seen in the publication of the LC-OCD manufacturer [3].

A FluoroMax-4 spectrofluorometer (HORIBA Scientific, Japan) equipped with a $150 \mathrm{~W}$ xenon lamp and a $1 \times 1 \mathrm{~cm}$ quartz cell with four optical windows was used to characterize the fluorescent substances (i.e., proteins, humics) in EfOM. Excitation and emission scans were performed from 240 to $400 \mathrm{~nm}$ and 290 to $550 \mathrm{~nm}$, respectively, with a step of $5 \mathrm{~nm}$ and a slit number of $5 \mathrm{~nm}$. The signal output was given in terms of the ratio between corrected raw signal detector and corrected raw reference detector in order to compensate the system for background fluctuations with time. Under the same conditions, fluorescence spectra for Milli-Q water were subtracted from the spectra of EfOM to eliminate water Raman scattering and to reduce other background noise. The fluorescent intensity of EfOM was given in Raman Unit (RU) normalized to the maximum raw Raman peak intensity of Milli-Q water [5].

\section{RESULTS AND DISCUSSION}

\subsection{EfOM Characterization Before and After Filtration}

The LC-OCD profiles of the EfOM sample, the UF (RC10kD) permeate, and the NF (MPF200D) permeate are shown in Figure 3. The quantitative results on all fractions of these three samples are listed in Table 1.

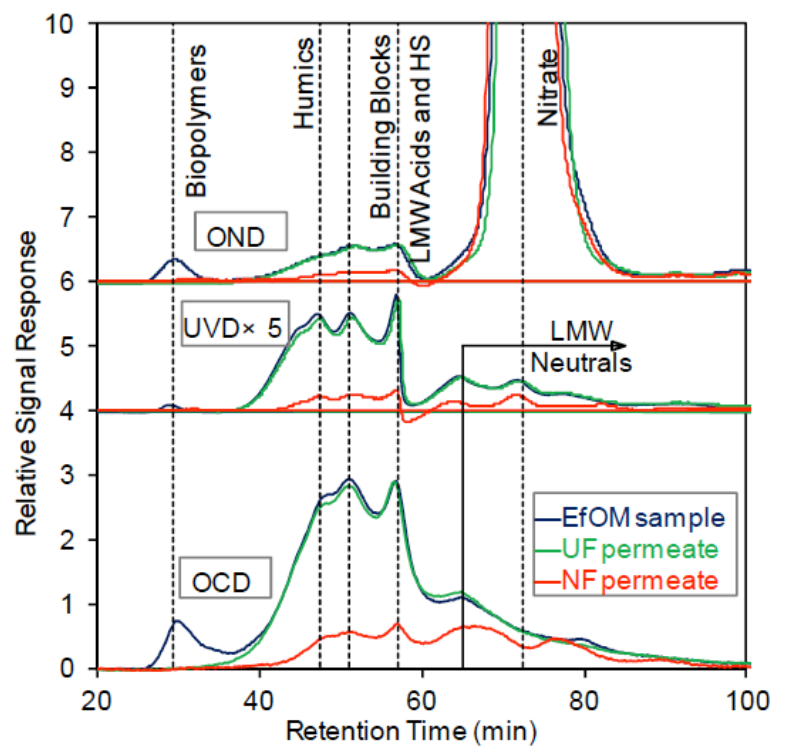

Figure 3: LC-OCD profiles of EfOM during sequential UF (RC10kD) - NF (MPF200D) filtration array. 
Table 1: LC-OCD Quantitative Results of EfOM During Sequential UF (RC10kD) - NF (MPF200D) Filtration Array

\begin{tabular}{|c|c|c|c|c|c|c|}
\hline \multirow{2}{*}{ Fraction } & \multicolumn{2}{|c|}{ EfOM sample } & \multicolumn{2}{|c|}{ UF permeate } & \multicolumn{2}{|c|}{ NF permeate } \\
\hline & OC (mg/L) & Percent (\%) & OC (mg/L) & Removal (\%) & $\mathrm{OC}(\mathrm{mg} / \mathrm{L})$ & Removal (\%) \\
\hline TOC & 4.8 & 100 & 4.3 & 10.4 & 1.1 & 74.4 \\
\hline Hydrophobic OC & 0.3 & 6 & 0.1 & 66.7 & 0 & 100 \\
\hline Chromatographic OC & 4.5 & 94 & 4.2 & 6.7 & 1.1 & 73.8 \\
\hline Biopolymers & 0.3 & 6 & 0 & 100 & 0 & - \\
\hline Humics & 2.4 & 50 & 2.4 & 0 & 0.3 & 87.5 \\
\hline Building blocks & 1 & 21 & 1 & 0 & 0.4 & 60 \\
\hline LMW acids & 0 & 0 & 0 & - & 0 & - \\
\hline LMW neutrals & 0.8 & 17 & 0.8 & 0 & 0.4 & 50 \\
\hline
\end{tabular}

For the EfOM sample, the chromatographic organic carbon (OC) accounted for $94 \%$ of TOC, indicating that nearly all organics in EfOM sample were hydraulic and could be well analyzed by LC-OCD. According to the quantitative calculation, the $\mathrm{OC}$ of humics and building blocks, LMW neutrals, biopolymers and hydrophobic organics accounted for $71 \%, 17 \%, 6 \%$ and $6 \%$ of TOC respectively. In addition, no LMW acids (i.e., easily biodegradable compounds) were found, indicating the good biological performance of that WWTP. Humics and building blocks - the normally refractory compounds - were the largest fractions of EfOM, showing that physical/chemical processes (e.g., adsorption/oxidation) rather than biological treatment should be preferred for post-treatment. These corresponded to the normal characteristics of EfOM $[1,14]$. Further calculations on biopolymers (i.e., the key potential foulants, especially for MF/UF) showed that its $\mathrm{C} / \mathrm{N}$ was 3.2 and thus proteins accounted for $94 \%$ of the biopolymers based on the assumption suggested by the LC-OCD manufacturer that all organic nitrogen in biopolymers originated from the proteins with a $\mathrm{C} / \mathrm{N}$ of 3. This indicated that proteins rather than polysaccharides were the dominant fractions of biopolymers in this study, which directly benefited from the addition of OND - the recent development of LCOCD. In previous studies [15,16] using LC-OCD without OND, biopolymers were usually regarded as polysaccharides due to the absence of OND information.

From the comparison of UF (RC10kD) permeate and EfOM, biopolymers were completely removed while other fractions were nearly unchanged, indicating that UF rejected only biopolymers. This was reasonable because the biopolymers and humics detected by LC-OCD usually had a MW of over $20 \mathrm{kD}$ and below $1 \mathrm{kD}$, respectively, which was also well above and below the MWCO of the UF membrane (10 $\mathrm{kD}$ ). In addition, hydrophobic organics were also significantly removed, possibly due to the size exclusion and/or adsorption by the UF.

From the comparison of NF (MPF200D) permeate and UF (RC10kD) permeate, the removal of humics, building blocks and LMW neutrals was $87.5 \%, 60 \%$ and $50 \%$, respectively, showing that the NF rejected most humics and building blocks and a significant part
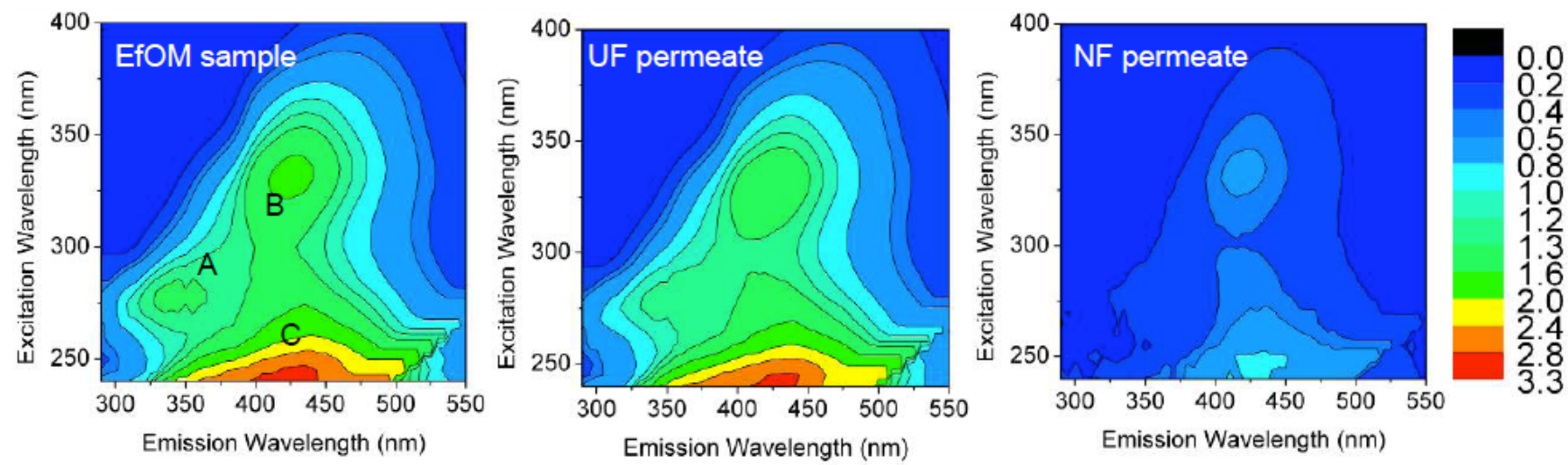

Figure 4: F-EEM contours of EfOM during sequential UF (RC10kD) - NF (MPF200D) filtration array. 
of the LMW neutrals mainly due to the size exclusion and the potential electrostatic interaction.

The F-EEM contours of the EfOM sample, the UF (RC10kD) permeate and the NF (MPF200D) permeate are shown in Figure 4. In the contour of the EfOM sample, three peaks were readily identified as $A$ (Ex/Em: 275-280/320-340 nm) for tryptophan proteinlike substances, B (Ex/Em: 330-335/415-430 nm) for primary humic-like substances and C (Ex/Em: 240250/410-440 nm) for secondary humic-like substances, showing the normal fluorescent characteristics of EfOM [5]. Compared with EfOM, peak A disappeared in the UF permeate, indicating that tryptophan protein-like substances were completely rejected by this UF with MWCO of $10 \mathrm{kD}$. Compared with the UF permeate, the intensities of peaks $B$ and $C$ significantly decreased in the NF permeate, showing that humics and building blocks were significantly rejected by this NF with
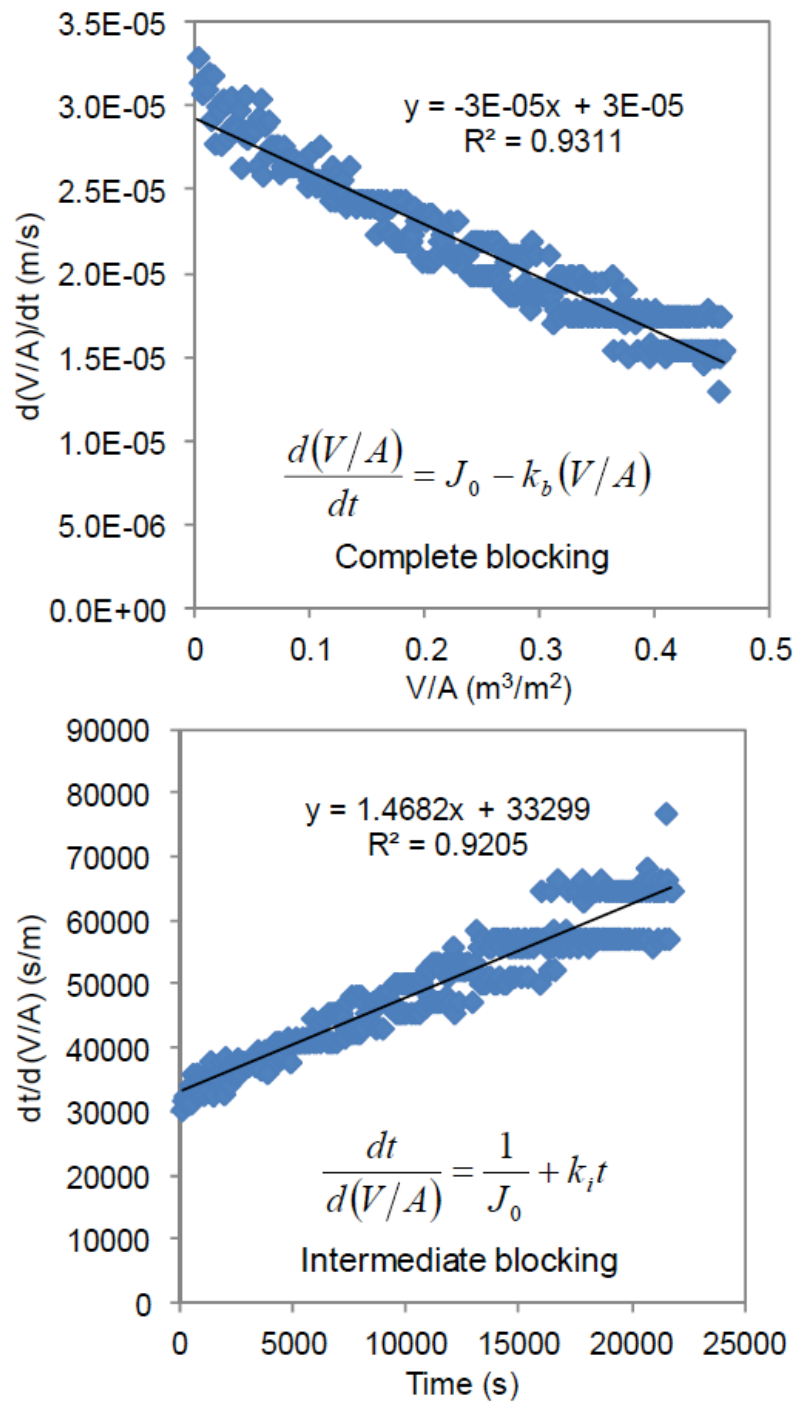

Figure 5: Correlations of filtration models for the UF (RC10kD).
MWCO of 200 D. Thus, the results of F-EEM were in agreement with those of LC-OCD.

\subsection{EfOM Fouling Potential}

From the above analysis of EfOM characterization before and after filtration, the UF (RC10kD) rejected only macromolecular biopolymers. Fouling of the UF should be caused by biopolymers and thus could be regarded as the fouling potential of macromolecular biopolymers. Similarly, the NF (MPF200D) rejected most humics and building blocks and a significant part of the LMW neutrals. Thus the fouling of the NF should characterize the fouling potential of low to intermediate MW organics (including humics, building blocks and LMW neutrals) to some extent.

According to the above-mentioned constantpressure filtration equations, fouling mechanism
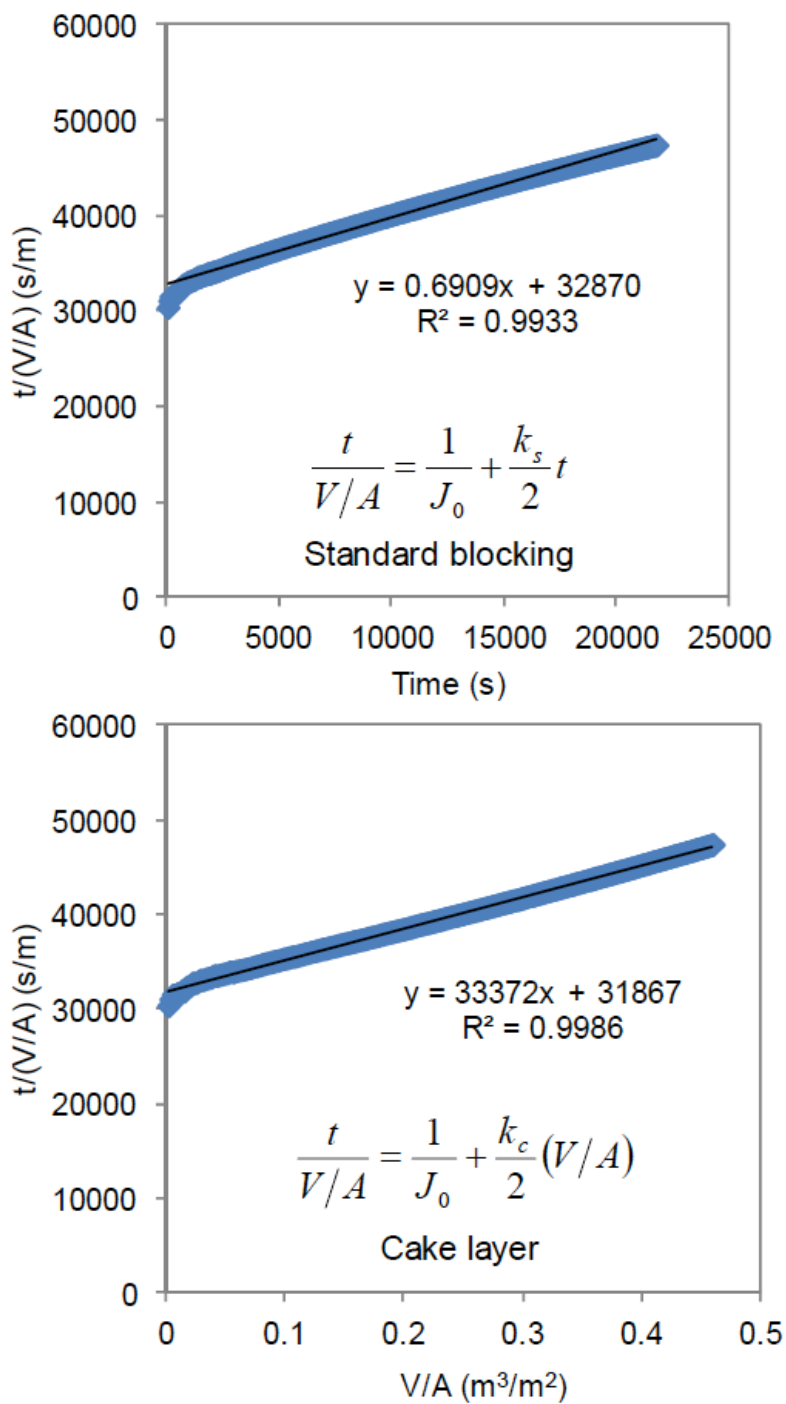
analyses of the filtration process of the UF (RC10kD) and the NF (MPF200D) are showed in Figures $\mathbf{5}$ and $\mathbf{6}$, respectively. For both filtration processes, the characteristic curves of cake layer model and standard blocking model showed very good linearity, indicating the simultaneous occurrence of cake layer and standard blocking. In addition, the discontinuity of data points in the characteristic curves of the complete blocking model and intermediate blocking model, especially for the NF, was mainly due to the numerical differentiation of $d(V / A) / d t$ and $d t / d(V / A)$ using the adjacent two data pairs (i.e., $\left[(V / A)_{2}-(V / A)_{1}\right] /\left(t_{2}-t_{1}\right)$ and $\left.\left.\left(t_{2}-t_{1}\right) \Lambda(V / A)_{2}-(V / A)_{1}\right]\right)$.

It was interesting that cake layer and standard blocking occurred simultaneously during the filtration process of both the UF (RC10kD) and the NF (MPF200D). This might be due to the heterogeneous nature of EfOM (as seen in Figure 3), which contained macromolecular biopolymers with wide MW range (several ten to several hundred $\mathrm{kD}$ ) as well as low to
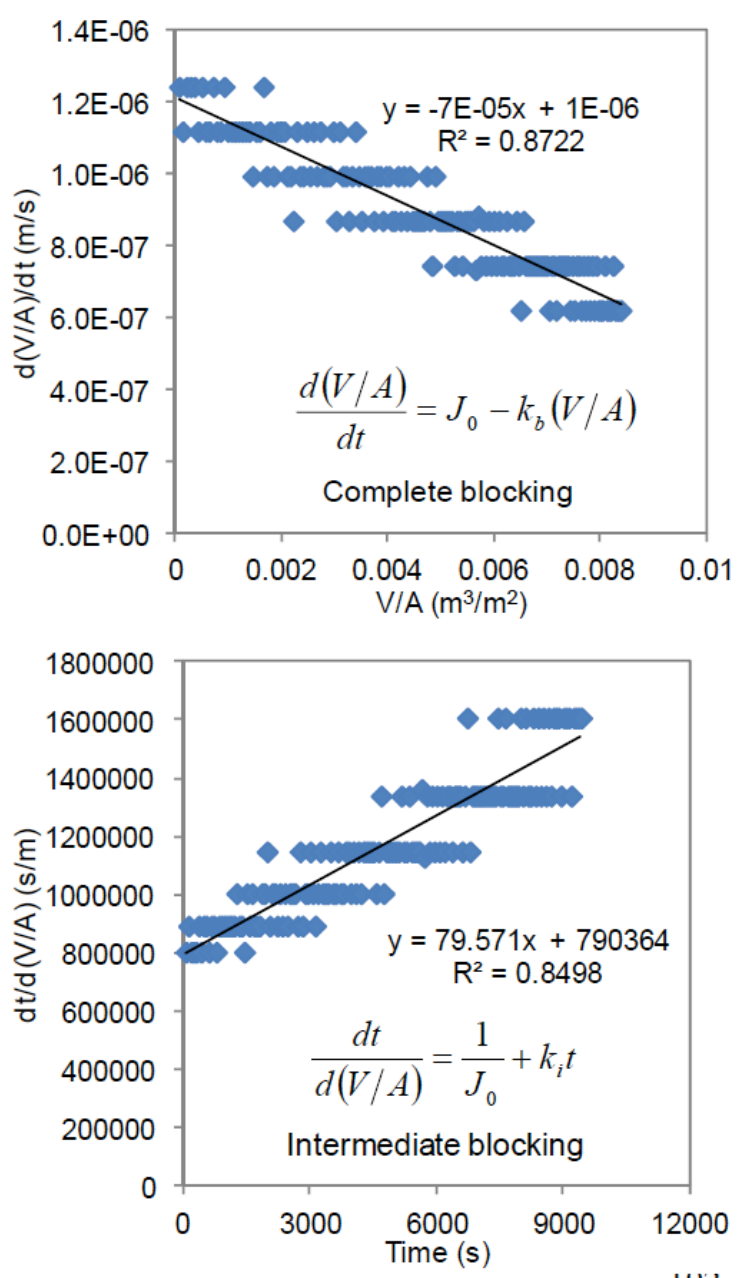

192 intermediate MW organics with wide MW range (several ten to several thousand D). Thus, a possible explanation is proposed in Figure 7. For the UF, it was reasonable that the rejected biopolymers with $\mathrm{MW}>10$ $\mathrm{kD}$ (mainly proteins) could form a cake layer while those with $\mathrm{MW}<10 \mathrm{kD}$ (mainly polysaccharides) could penetrate membrane pores and/or channels of the cake layer resulting in standard blocking. Similarly, the NF rejected low to intermediate MW organics with MW $>200 \mathrm{D}$ resulting in a cake layer as well as some organics with $\mathrm{MW}<200 \mathrm{D}$ in membrane pores and/or channels of the cake layer resulting in standard blocking. In a recent study, Yang et al. [17] reported that the fouling (cake) layer caused by major foulants ( $\beta$-D-glucopyranose polysaccharides) could be blocked again by minor foulants (proteins, nucleic acids and $\alpha$ D-glucopyranose polysaccharides) during constantpressure dead-end microfiltration of sludge supernatant. However, the detailed mechanisms behind the occurrence of simultaneous cake layer and standard blocking should be investigated further.
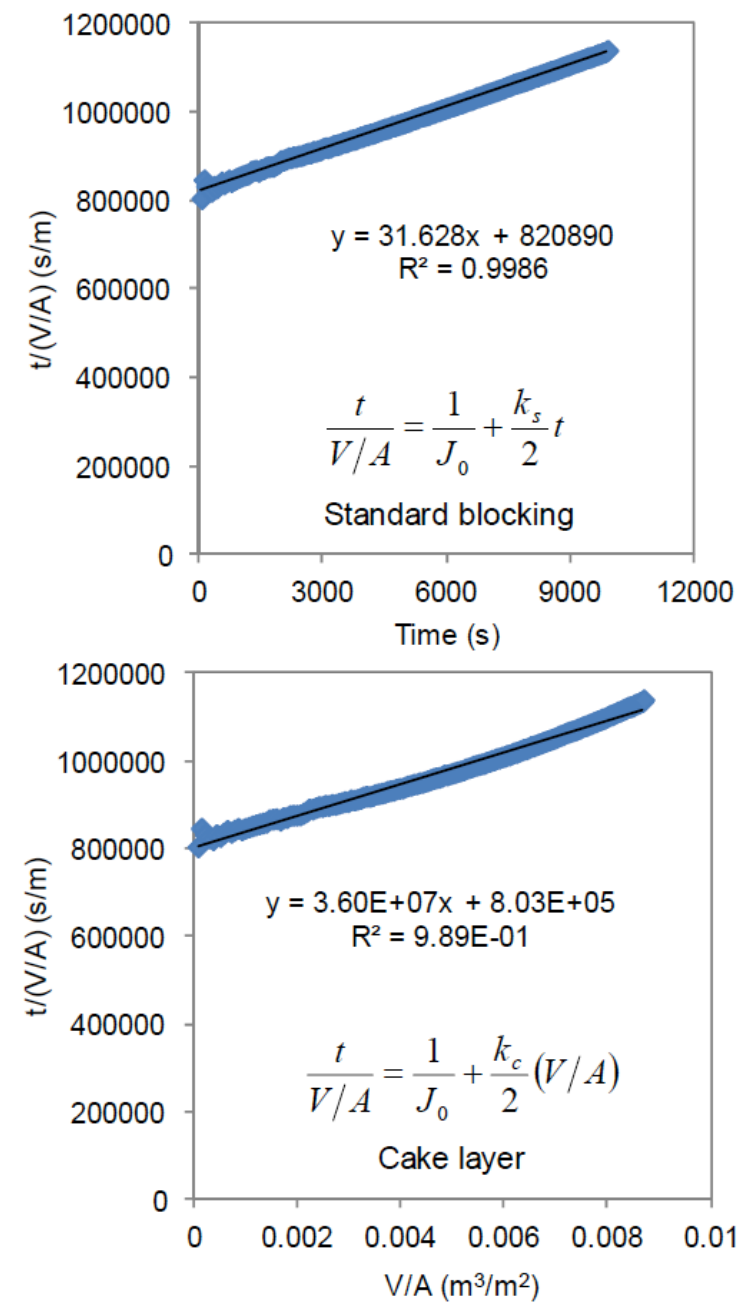

Figure 6: Correlations of filtration models for the NF (MPF200D). 


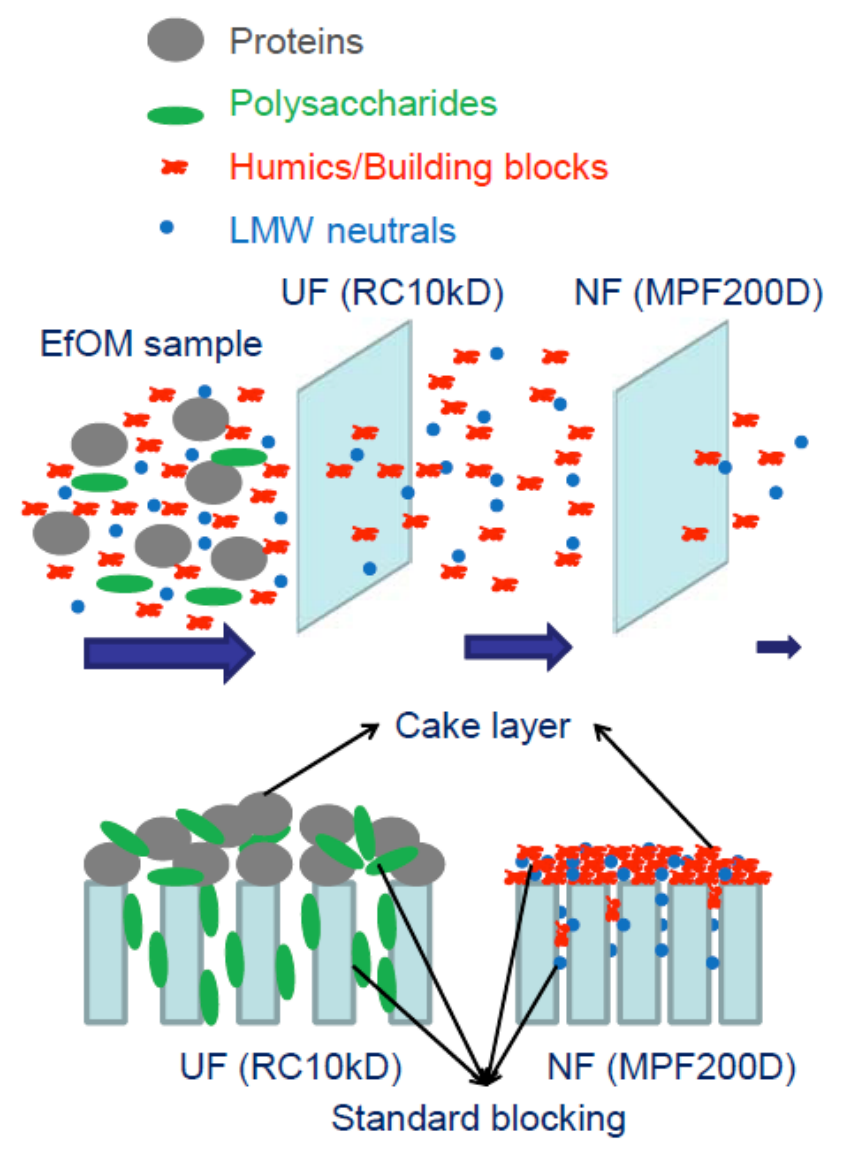

Figure 7: Possible schematic explanation of simultaneous occurrence of cake layer and standard blocking.

Based on the above analysis, the two fouling indices correlated from the cake layer model (i.e., $\mathrm{k}_{\mathrm{c}}$ in Equation 4) and standard blocking model (i.e., $k_{s}$ in Equation 2) can be adopted to characterize the fouling potential of macromolecular biopolymers through the UF (RC10kD) filtration and low to intermediate MW organics through the NF (MPF200D) filtration. For macromolecular biopolymers and low to intermediate MW organics, $k_{c}$ was $3.34 \times 10^{4}$ and $3.60 \times 10^{7} \mathrm{~s} / \mathrm{m}^{2}$, respectively, and $\mathrm{k}_{\mathrm{s}}$ was 0.69 and $31.631 / \mathrm{m}$, respectively. Compared with macromolecular biopolymers, low to intermediate $\mathrm{MW}$ organics had 1080 times higher $k_{c}$ and 46 times higher $k_{s}$, indicating their much higher fouling potential. This might be related to the lower MW (usually forming a more compact cake layer) and higher concentration (usually proportional to fouling potential) of low to intermediate MW organics than macromolecular biopolymers in EfOM.

It should be noted that the fouling potential of EfOM during membrane filtration would depend on mainly the membrane characteristics (e.g., pore size or MWCO, charge). In this study, a tight UF with MWCO of $10 \mathrm{kD}$ was used and achieved complete rejection of macromolecular biopolymers (major proteins and minor polysaccharides) in EfOM, which resulted in the simultaneous occurrence of cake layer and standard blocking. In some studies $[18,19]$ using loose UF (e.g., $150 \mathrm{kD}$ ), the fouling mechanism of cake layer and/or initial pore blocking followed by cake layer was identified and might be related to the partial rejection of biopolymers (mainly proteins) by the loose UF membrane. The NF (MWCO of $200 \mathrm{D}$ ) filtration of UF permeate in this study could be regarded as the fouling potential of the fractions with low to intermediate MW of 200-10k D in EfOM (i.e., the fractions except biopolymers), which little information on this was available in the literature Thus, the sequential UF-NF filtration array would be helpful to explore the fouling potential of individual fractions of EfOM and investigate the applicability of hybrid UF-NF process for tertiary treatment and reuse of biologically treated secondary effluent.

\section{CONCLUSIONS}

EfOM characterization by advanced analytical methods including LC-OCD and F-EEM and fouling potential through constant-pressure dead-end filtration tests with a sequential UF (RC10kD) and NF (MPF200D) array were investigated in this study. EfOM consisted of humics and building blocks (71\%), LMW neutrals $(17 \%)$, biopolymers $(6 \%)$ and hydrophobic organics $(6 \%)$ according to organic carbon fractions. Proteins rather than polysaccharides were identified as the main components of biopolymers from LC-OCD. The UF rejected only biopolymers and The NF rejected most humics and building blocks and a significant part of the LMW neutrals. Simultaneous occurrence of cake layer and standard blocking during the filtration process of both the UF and NF was identified according to the constant-pressure filtration equations, possibly due to the heterogeneous nature of EfOM containing macromolecular biopolymers with wide MW range (several ten to several hundred $\mathrm{kD}$ ) as well as low to intermediate MW organics (including humics, building blocks and LMW substances) with wide MW range (several ten to several thousand D). The major foulants (mainly proteins for the UF and humics/building blocks for the NF) could form a cake layer while the minor foulants (mainly polysaccharides for the UF and LMW neutrals for the NF) could penetrate membrane pores and/or channels of the cake layer resulting in standard blocking. Thus the corresponding two fouling indices ( $\mathrm{k}_{\mathrm{c}}$ for cake layer and $\mathrm{k}_{\mathrm{s}}$ for standard blocking) from the UF and the NF could characterize the fouling potential 
of macromolecular biopolymers and low to intermediate MW organics, respectively. Compared with macromolecular biopolymers, low to intermediate MW organics had much higher fouling potential (1080 times higher $k_{c}$ and 46 times higher $k_{s}$ ) mainly due to their lower MW and higher concentration.

\section{ACKNOWLEDGEMENT}

This work has been financed by the KAUST-UIUC Academic Excellence Alliance (AEA) Project entitled Anaerobic Membrane Bioreactor (AnMBR) with Nanofiltration (NF) Membrane.

\section{REFERENCES}

[1] Shon HK, Vigneswaran S, Snyder SA. Effluent organic matter (EfOM) in wastewater: Constituents, effects, and treatment. Crit Rev Env Sci Tec 2006; 36(4): 327-74. http://dx.doi.org/10.1080/10643380600580011

[2] Laabs CN, Amy G, Jekel M. Understanding the size and character of fouling-causing substances from effluent organic matter (EfOM) in low-pressure membrane filtration. Environ Sci Technol 2006; 40: 4495-9. http://dx.doi.org/10.1021/es060070r

[3] Huber SA, Balz A, Abert M, Pronk W. Characterisation of aquatic humic and non-humic matter with size-exclusion chromatography - organic carbon detection - organic nitrogen detection (LC-OCD-OND). Water Res 2011; 45: 879-85. http://dx.doi.org/10.1016/j.watres.2010.09.023

[4] Huber SA, Frimmel FH. Direct gel chromatographic characterization and quantification of marine dissolved organic carbon using high-sensitivity DOC detection. Environ Sci Technol 1994; 28: 1194-7. http://dx.doi.org/10.1021/es00055a035

[5] Henderson RK, Baker A, Murphy KR, Hambly A, Stuetz RM, Khan SJ. Fluorescence as a potential monitoring tool for recycled water systems: A review. Water Res 2009; 43: 86381. http://dx.doi.org/10.1016/j.watres.2008.11.027

[6] Hermans PH, Bredee HL. Principles of the mathematical treatment of constant-pressure filtration. J Soc Chem Ind 1936; 55T: $1-4$

[7] Hermia J. Constant pressure blocking filtration lawsapplication to power-law non-Newtonian fluids. Trans IChemE 1982; 60A: 183-7.

[8] Ho CC, Zydney AL. A combined pore blockage and cake filtration model for protein fouling during microfiltration. $J$ Colloid Interface Sci 2000; 232: 389-99.

http://dx.doi.org/10.1006/jcis.2000.7231
[9] Cho JW, Amy G, Yoon YM, Sohn J. Predictive models and factors affecting natural organic matter (NOM) rejection and flux decline in ultrafiltration (UF) membranes. Desalination 2002; 142: 245-55.

http://dx.doi.org/10.1016/S0011-9164(02)00206-0

[10] Bolton G, LaCasse D, Kuriyel R. Combined models of membrane fouling: Development and application to microfiltration and ultrafiltration of biological fluids. J Memb Sci 2006; 277: 75-84. http://dx.doi.org/10.1016/j.memsci.2004.12.053

[11] Wei CH, Laborie S, Ben Aim R, Amy G. Full utilization of silt density index (SDI) measurements for seawater pretreatment. J Memb Sci 2012; 405-406: 212-8. http://dx.doi.org/10.1016/j.memsci.2012.03.010

[12] Boerlage SFE, Kennedy MD, Dickson MR, El-Hodali DEY, Schippers JC. The modified fouling index using ultrafiltration membranes (MFI-UF): characterisation, filtration mechanisms and proposed reference membrane. J Memb Sci 2002; 197: $1-21$. http://dx.doi.org/10.1016/S0376-7388(01)00618-4

[13] Wang F, Tarabara VV. Pore blocking mechanisms during early stages of membrane fouling by colloids. J Colloid Interface Sci 2008; 328: 464-9.

http://dx.doi.org/10.1016/j.jcis.2008.09.028

[14] Jarusutthirak C, Amy G. Understanding soluble microbial products (SMP) as a component of effluent organic matter (EfOM). Water Res 2007; 41: 2787-93. http://dx.doi.org/10.1016/j.watres.2007.03.005

[15] Huber SA. Evidence for membrane fouling by specific TOC constituents. Desalination 1998; 119: 229-34. http://dx.doi.org/10.1016/S0011-9164(98)00162-3

[16] Rosenberger S, Evenblij H, Poele ST, Wintgens T, Laabs C. The importance of liquid phase analyses to understand fouling in membrane assisted activated sludge processes six case studies of different European research groups, J Memb Sci 2005; 263: 113-26. http://dx.doi.org/10.1016/j.memsci.2005.04.010

[17] Yang Z, Juang YC, Lee DJ, Duan YY. Pore blockage of organic fouling layer with highly heterogeneous structure in membrane filtration: Role of minor organic foulants. J Memb Sci 2012; 411-412: 30-4. http://dx.doi.org/10.1016/j.memsci.2012.04.010

[18] Zheng $X$, Ernst M, Jekel M. Identification and quantification of major organic foulants in treated domestic wastewater affecting filterability in dead-end ultrafiltration. Water Res 2009; 43: 238-44.

http://dx.doi.org/10.1016/j.watres.2008.10.011

[19] Filloux E, Labanowski J, Croue JP. Understanding the fouling of UF/MF hollow fibres of biologically treated wastewaters using advanced EfOM characterization and statistical tools. Bioresour Technol 2012; 118: 460-8. http://dx.doi.org/10.1016/j.biortech.2012.05.081

\section{DOI: http://dx.doi.org/10.6000/1929-6037.2012.01.02.7}

(C) 2012 Wei and Amy; Licensee Lifescience Global.

This is an open access article licensed under the terms of the Creative Commons Attribution Non-Commercial License (http://creativecommons.org/licenses/by-nc/3.0/) which permits unrestricted, non-commercial use, distribution and reproduction in any medium, provided the work is properly cited. 